\title{
When Law Listens
}

\section{Simon Rose}

I was recently in Köln, Germany and took a boat trip on the vast River Rhine. I learnt that one side developed as a boundary of the Roman Empire while on the other bank were the "Germanic peoples." I imagined them looking across the huge divide, what they may have made of each other, and how long it was before the first bridge was built. Improvisation and law appear to be similarly far away from each other, representing opposing sides of experience: think of the law and you may well imagine police enforcement; think of improvisation and you might imagine a group of musicians or dancers working together in a space. Improvisation and the law seem utterly dissimilar. But compare the mainstream theatre and the courtroom. Unlike such theatre in which improvisation is, in practice, most often carefully designed out of the process, negated by the desire to fix a repeatable production, the theatre of the courtroom does not perform a prescripted event. The outcome in a court case has to be not-pre-determined by the players, or unknown. It comes about through a complex network of interactions, many of which are famously formalised, but other factors, like, for example, the influence a witness may create by the manner in which they appear and their use of particular language are not formalised and yet they can influence judges and juries as well as the wider audience (Daniloff qtd. in Rose, The Lived Experience 129). As such, improvisation is already integral to the processes of law. For this reason, in part, so much fiction, from Shakespeare to Netflix, exploits legal proceedings as a dramatic device capable of readily reflecting the many sides of human experience. As unpredictable events unfold in the process of law, improvisation is found within its processes.

Improvisation is also present in the formation of written laws. Deborah Daniloff, a practicing lawyer from the US, recounts how the law itself can develop through an improvisatory process. Daniloff cites the co-opting of the legal right to privacy in establishing women's legal right to abortion as improvisatory (Roe vs. Wade, 1973), and how integrated schooling was only achieved through legislation that established racially segregated schools as unequal (Brown vs. Board of Education, Topeka, 1954). Daniloff describes these improvisational developments as a reflection of the political shifts of the time.

I'll stand back briefly and consider the very idea of improvisation. The term improvisation is used in different ways and it may be misleading to presuppose a shared agreement about the term's meaning. I've already used the descriptors not-pre-determined and unknown with respect to outcomes and I can add to this: creativity, adaptability, contingency, recognition of the uniqueness of a given situation and its potential, collaboration, emergence, immediacy, negotiation, and doing. More broadly, its use here also refers to improvisation as a social process and a process of learning that is found across experience (Rose, "Articulating Perspectives"; Leone; and others). Through this social context, improvisation embodies an ethical dimension (Rose, Lived Experience 60-64). Simply put, regardless of whether improvisation is taking place in music, drama, education, law, politics, health-care, sport, the family, or elsewhere, the commonality of its features are experienced within its social context through which themes may be viewed as shared. I will briefly illustrate the interdisciplinary potential of improvisation. In the analysis of themes of improvisation among musicians, creatively seeking outcomes that are not-pre-determined was described as an ongoing process of learning (Rose, "Improvisation"). Improvisation's significant relation with learning has also been described in other research (Sawyer, "Creative Teaching," "Improvisation and Teaching") and Livingstone and Borko found that experienced teachers use improvisation in every lesson. Additionally, improvisers, for example in music, develop high-level skills in relation to these descriptors based upon personalised repertoire of materials, strategies, and approaches that are developed over decades of practice. Improvisation's thematic exchange is found in music and arts and also in different areas of professional and everyday practices (Leone, Jackson and Delehanty, and others).

On May 29-30, 2015 I participated in the Sonic Arts Research Centre's (SARC, UK) symposium: Just Improvisation: Enriching Child Protection Law through Musical Techniques, Discourses and Pedagogies. The final panel and plenary session featuring Her Honour Judge Patricia Smyth, His Honour Judge Brian Sherrard, and Queen's Council Siobhan Keegan (Vice-chair of the bar of Northern Ireland) was striking in its clarity. On the face of it the very idea that two judges and a QC should be discussing improvisation and its relation to their everyday professional work had a slightly surreal quality, suggested perhaps by the grandeur of their titles. However, each described their seeking to work in a manner that is adaptable, flexible, and creative-as the human situations they address, on a day-to-day basis, call for a facility for immediacy and adaptability. These are distinguished individuals whose expertise and acumen are necessary for interpreting and implementing complex legal processes. Their understanding of creativity and adaptability in relation to legal processes is valuable for law and improvisation research. 
Improvisation is about doing, and paradoxically improvisation discourse may, by its nature, easily privilege the academic over the activity of those working "in the field." However, discussion at the symposium of improvisation's relevance in the legal processes was very much situated in the breadth of experience and practice. Through accounts of child protection, the pressing need for adaptable response within the process and flexibility in arriving at just decision-making became highlighted. In this way improvisation is tacitly embedded in the legal process.

Family Judge Smyth described how there was "huge scope" for flexibility and creativity in order to reach the right solution to an individual family problem. As a mother of four Smyth also described how her experience taught her that children require different kinds of care, and different amounts of parenting contact as "a matter of common sense." This view differed from what she described as the inadequacy of the rule-based, textbook approach when applied to the infinite variety of family problems - there is a disjunction between the "one rule fits all" approach and the individuality of each case. While Smyth viewed creativity as important for reaching a just decision she also described how social workers seek to apply a textbook response in every case. In her view there is an anxiety about doing something different or thinking "outside the box"-as she put it: they are trained to not be creative.

The comparison here to processes in music making are striking: the score, "work," or text representing a piece of music is most often privileged as defining of the music, advocated by institutions, afforded cultural significance, funded and so on, while, at the same time, the ubiquitous practice of improvisation in music has been historically sidelined as "not serious" and institutionally negated in different ways, although this picture is changing. For law and music text is only part of the picture: the lived-experience of law and music only take place within human interactions in which the potential of improvisation is always present.

Judge Sherrard described the need to recognise the developing circumstances of a case. This, in his opinion, leads to the need to value opportunities offered through creativity and innovation. In music and other spheres of activity a feature of improvisation is the ability to respond to changing circumstancesallowing for and working with contingency. Between the enacted legal process and its social context there is a need for adaptability, flexibility, and creativity in seeking just decision-making and this forms an empowering part of the process. As there is always a complex set of relations that includes a multiplicity of implications, adaptability and inventiveness allow for the specificity of each individual case to be addressed. The need for a response that includes awareness of the improvisational dimension is clear-damaging situations may be prolonged or even made worse by means of, for example, an enforced parent/child separation that, once established, may prove irreversible.

In Judge Smyth's view the "huge scope to be creative" is engendered by the need for child protection: "It's a risky business" in which "every child and every family is different and we need a bespoke solution." Identifying and working with difference, the particularity of each case, situation, or musical encounter is a forte of improvisation - it leads to a "bespoke" outcome. Forming an appropriate perceptual and conceptual response requires adaptability and immediacy, features of improvisation that reference to text alone cannot achieve.

As improvisers make decisions in relation to emerging events, awareness of timing is central to practice. Judge Brian Sherrard discussed the timeframe for the legal process relating to child protection: how a proposed twenty-six-week rule (similar to that adopted in England as part of the Children and Families Act 2014, which was brought in to limit delay) if implemented in Northern Ireland, would create a further limitation, or "tightening-up" of procedures. Sherrard went on to describe the need for working flexibly, in an adaptable, creative manner before the case came to court, when issues were "flagged up." In one case the extension of the judicial process leading from a change of parental circumstances enabled a parent to keep a child, where an earlier judgment would have resulted in the child's removal. While time-guides exist for processing cases, these policies may also become a blunt instrument that counters the benefit of working responsively and creatively in seeking a just outcome.

Within improvisation research, listening is a cornerstone (Oliveros; Ediger; Fiumura; and others). Pioneer of the field Pauline Oliveros was present at the symposium and her session included participation in exercises and ideas associated with her long-term project "Deep Listening." Co-led with her partner lone, the session focussed on the nature of listening through self-reflective exercises. Oliveros's experiential session was an effective counterpoint to the cerebral activity we take for granted even in much music research. For those new to this sort of thing it may have seemed strange, moving through the space contemplating one another, thinking about a dream, focussing on feelings and the sense of self and others on that Sunday morning. It later became clear that listening was also conceptualised within the legal process. Judge Smyth described 
how the complex picture of law and child protection calls for a "holistic" response in order to reach just decisions; within this picture listening becomes centrally important.

Smyth explained how a key task for any judge was to convey to the individual that they have been listened to. This was underscored by Smyth's description of the vulnerability of many of those who have come before the court, some of whom she described as having "never been listened to." Poignantly, Smyth described how even when a mother was to lose her child and "was heard in court," she was better able to understand the decision, and how human dignity and respect can be acknowledged by attentive listening during the legal process.

Child protection processes and procedures take place in what the panel described as the "high-risk" context. There have been a number of well publicised, tragic cases of child deaths in the UK that have asked very difficult and incriminating questions of professionals involved in the child protection process. The role of listening in good child protection practice requires careful clarification. Listening, like improvisation, is used in ways agents choose, and, as we know, listening is also exploited through advertising and marketing, as well as through mass surveillance (NSA, GCHQ). Additionally, the asymmetrical power relations of the courtroom also question any assumptions about the nature of communication.

So, what does listening suggest here? The court is the performative arena in which the possibility of a just solution may be arrived at, a helpful process implemented. Within the specific dynamic of child protection there are different connotations. The common notion of the "fair hearing" is of course present; it could also, to some extent, reflect an aspect of "talk therapy" that depends upon the quality of listening through which the airing of issues allows a new perspective to be achieved (Rogers). There is also the related suggestion of listening as a cathartic process (Nash; Triscott). These themes are more explicitly addressed for law by Winick \& Wexler, who discuss therapeutic jurisprudence's concern for the unintended social effects of law's implementation. The overall impression that the panel conveyed was that the significance of listening was grounded by an empathy for the human issues in question and the need to find just solutions to difficulties that carry implications affecting the trajectory and quality of lives of those affected.

The interdisciplinary study of improvisation in music and law forms an exchange of understanding. Improvisation presents the musician with the possibility of creating a new piece of music in each encounter. This mode of working creatively with changing circumstances is mirrored by Siobhan Keegan QC's statement that "the out-workings of trials are myriad and surprise me all the time." Musical improvisation develops through the relations involved and as such valuing different contributions is key to the creative process. Keegan also stressed the need to acknowledge the "one hundred and fifty shades of grey" arising from each case's difference (a theme which was echoed at the symposium by other participants from the legal domain). The inadequacy of a "one rule fits all" (Smyth) approach was squarely challenged, becoming a call to recognise the difference that is always present by listening to what is there. And Keegan's description of the "myriad out-workings" of child protection cases forms an interdisciplinary descriptor of improvisation. As creative improvisation in music values difference and the particularity of a given event, Keegan's term "bespoke solution" captures this key feature of improvisation's potential. A unique feature of improvisation, and free improvisation in particular, is the ability to embrace and celebrate the particularity of individuals' and groups' different ways of doing things.

Accounts presented at the Just Improvisation Symposium of those involved in child protection vividly illustrate the complexity of seeking just decisions. As Judge Smyth says, a "holistic" view of family justice needs to go beyond reference to "the book" alone. Indeed, the urgency of child protection demands improvisational features of listening, adaptability, working with contingency and seeking creative solutions. While improvisation in music is of a different order to child protection, consideration of the processes involved is revealing. For music and law, rather than the overreliance upon text, improvisation offers engagement in the immediacy of what is occurring, in being responsive and creative. And, as in other domains (pedagogy, health-care, sport, and so on) improvisation as a human capability comes to the fore through the "real-world" social setting. The accounts of child protection and law provide an example of improvisation in action while the urgency of the circumstances create a sharpened focus. Within child protection there is a clear need to acknowledge the benefits of working with skilled adaptability and creativity, an integrated approach to listening contextualised by the nature of those present and the particularity of changing circumstances. This leads to the question of how to further develop ways of acknowledging the significance of such creativity within legal practice. And, to consider how knowledge and the experience of creative improvisation may become more widely disseminated, shared, and embedded within day-to-day practice and training. 
I began with the image of the river, its two distant banks and the separated practices of law and improvisation in music. However, those involved in the work of child protection and its legal processes clearly articulate the need for creative thinking and adaptable approaches in actively seeking just, effective solutions - in the terms of reference used by improvisation research, they are already improvisers. The articulation of the need to address different individuality and changing circumstances in a creative manner offers a novel, interdisciplinary descriptor of improvisation that becomes relevant for music and beyond. Although it may not have seemed so, we are standing on the same bank.

\section{Works Cited}

Ediger, Jeffrey. "Imaginative Listening and the Reverberations of the World." The Tuning of the World: First International Conference on Acoustic Ecology. Banff Centre for the Arts. 8-14 Aug. 1993.

Fiumura, Gemma. The Other Side of Language. Routledge, 1990.

Jackson, Phil and Hugh Delehanty. Eleven Rings: The Soul of Success. Penguin, 2014.

Leone, Ludovica. "A Critical Review of Improvisation in Organizations: Open Issues and Future Research Directions." Druid Opening Up Innovation: Strategy, Organization and Technology. Imperial College London Business School. 16-18 June 2010.

Livingston, Carolyn and Borko, Hilda. Expert-Novice Differences in Teaching: A Cognitive Analysis and Implications for Teacher Education. Sage, 1989.

Nash, Polly. "Listening to Stories from Guantanamo." On Listening, edited by Angus Carlyle and Cathy Lane, Uniformbooks, 2015, pp. 167-171.

Nettl, Bruno and Melinda Russell, editors. In the Course of Performance: Studies in the World of Musical Improvisation. U of Chicago P, 1998.

Oliveros, Pauline. Deep Listening: A Composer's Sound Practice. iUniverse, 2005.

Rogers, Carl. On Becoming a Person: A Therapist's View of Psychotherapy. Constable, 1998.

Rose, Simon. "Articulating Perspectives of Free Improvisation for Education." MA Thesis. Middlesex University, UK, 2008.

---. "Improvisation, Music and Learning: An Interpretive Phenomenological Analysis." Diss. Glasgow Caledonian University, UK, 2013.

---. The Lived Experience of Improvisation: In Music, Learning and Life. Intellect, 2017.

Sawyer, R. Keith. "Creative Teaching: Collaborative Discussion as Disciplined Improvisation." Educational Researcher, vol. 33, no. 2, 2004, pp. 12-20, doi.org/10.3102/0013189X033002012.

---. "Improvisation and Teaching." Critical Studies in Improvisation / Études critiques en improvisation, vol. 3, no. 2, 2008, www.criticalimprov.com/issue/view/40.

Translatingimprovisation.com/portfolio/symposium

Triscott, Nicola. "Attending Rwanda's Post-Genocide Reconciliation Workshops.” On Listening, edited by Angus Carlyle and Cathy Lane, Uniformbooks, 2015, pp. 176-179.

Winick, Bruce and Derrick B. Wexler, editors. Judging in a Therapeutic Key: Therapeutic Jurisprudence and the Courts. Carolina Academic P, 2003. 